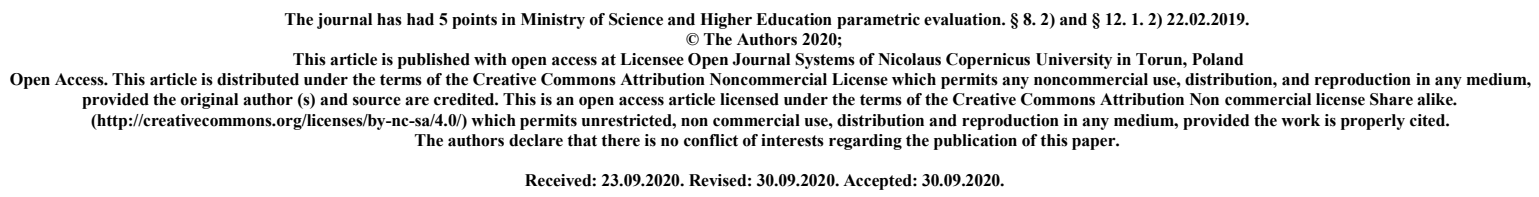

\title{
Electroconvulsive therapy (ECT) - brief history and guidelines
}

Krzewicka-Romaniuk Ewa ${ }^{1}$, Siedlecka Dagna ${ }^{1}$, Romaniuk Artur ${ }^{2}$

1. Department of Pathophysiology, Medical University of Lublin, Lublin, Poland

2. Praktyka Lekarza Rodzinnego „Familia” ul. Niepodległości 29, 21-040 Świdnik

Key words: Electroconvulsive therapy; ECT; ect side effects;

\begin{abstract}
Electroconvulsive therapy (ECT) is one of the most effective and safe methods of treatment used in psychiatry. The history of ECT in Poland dates back to 1861, when Vilnius doctor Klemens Maleszewski successfully applied electricity obtained from a galvanic cell to treat a patient with catatonia. The modern history of the use of electricity to induce seizures dates back to 1938, when Bini and Cerletti performed the first ECT on a patient suffering from paranoid schizophrenia. Although ECT is thought to be a very safe, well-known and effective procedure, patients are still afraid of undergoing ECT due to bad reputation of this method.
\end{abstract}




\section{INTRODUCTION}

Electroconvulsive therapy (ECT) is one of the most effective and safe methods of treatment used in psychiatry. Worldwide one million ECT procedures are performed annually. Undoubtedly the advantage of ECT is a very quick therapeutic response. It is observed significantly earlier than in the case of pharmacotherapy. Positive effects can be observed already in the first week of treatment.

Although efficacy of ECT in deep depressive disorders reaches $70-90 \%$, its use is limited due to the belief that this method has numerous side effects. ECT therapy is indeed associated with the possibility side effects, but they appear relatively rarely. Most often they are mild, definitely not life-threatening.[1]

\section{HISTORY OF ELECTROCONVULSIVE THERAPY}

A pioneer of electroconvulsive therapy in Poland (and perhaps also in the world) was the Vilnius doctor Klemens Maleszewski, who in 1861 successfully applied electricity obtained from a galvanic cell to treat a patient with catatonia. Unfortunately, the description of this case came to light after more than 100 years, in 1998. Interestingly, in another of his publications Maleszewski wrote that "electricity [...] gave doctors great hopes for treating madness, but now it is completely neglected".

The modern history of the use of electricity to induce seizures dates back to 1938 , when Bini and Cerletti performed the first electroconvulsive treatment (ECT) on a patient suffering from paranoid schizophrenia. The positive symptoms disappeared in this patient after several procedures. For several dozen consecutive years, electroconvulsive therapy was used quite willingly, despite the high frequency of perioperative complications.[2] In the 1940s, psychiatrists began to experiment with curare, the muscle-paralyzing South American poison, in order to modify the convulsions. The introduction of suxamethonium (succinylcholine), a safer synthetic alternative to curare, in 1951 led to the more widespread use of "modified" ECT. A short-acting anesthetic was usually given in addition to the muscle relaxant in order to spare patients the terrifying feeling of suffocation that can be experienced with muscle relaxants.[3] This procedure turned out to be safe and nowadays systemic anesthesia and relaxation with scoline are standard during ECT.

The numerous publications appearing in the following years concerning disturbances of consciousness after procedure, persistent memory disorders or the neurotoxic effects of ECT resulted in a bad opinion about this method of therapy. Films such as "One Flew Over the Cuckoo's Nest" or information about ECT as a method of "personality changing" turned out to be so popular that for several years the use of ECT was almost abandoned.

The introduction of selective serotonin re-uptake inhibitors (SSRIs), serotonin and norepinephrine reuptake inhibitors (SNRIs), norepinephrine reuptake inhibitors (NRIs) and reuptake inhibitors (NRIs), safer and safer neuroleptics, was to be a remedy in the treatment of drug-resistant depression and severe psychoses, not responding to pharmacotherapy used so far. The experience of recent years has shown that this has not happened. As shown by the results of the Sequenced Treatment Alternatives to Relieve Depression (STAR-D) study, ECT remains the most effective method of treating drug-resistant depression with remission rates of approximately 50\%.[2]

\section{MECHANISM OF ACTION \& COURSE OF ELECTROCONVULSIVE THERAPY}

The mechanism of action of ECT is not known but may be related to alteration of neurotransmitter function in a manner similar to that of treatment with psychoactive agents.[4] 
Electroconvulsive therapy involves the application of electrical stimulation within the central nervous system, causing an epileptic seizure of a short and controlled duration.[3] Effective ECT techniques include: bilateral, bifrontal, and right unilateral electrode placement. Less urgently ill patients are often treated initially with right unilateral electrode placement. Nowadays brief and ultrabrief pulse width stimuli are commonly used, what is associated with a more benign cognitive effect profile.[5]

The treatment is monitored using equipment that allows to assess its effectiveness. It takes about 15 minutes to awaken the patient from the moment of anesthesia to awakening, then vital signs are monitored for about half an hour - ECG recording, blood pressure, heart rate, and oxygen saturation of the blood. After this time, the patient, under the care of the staff, returns to the ward.

The treatment is painless, due to muscle relaxation, there are no convulsions, the patient is under the constant supervision of an anesthesiologist, psychiatrist and nurse.[3] There is no a priori fixed number of ECT in an acute course: patients should continue treatment with ECT until they remit or a plateau has been reached, or tolerability issues require interruption of the course.[5]

Usually, a series of treatments consists of 8 to 15 treatments performed 2-3 times a week. In some patients, further treatments are considered to maintain the achieved improvement.[3]

\section{INDICATIONS}

The indications for ECT include:

- conditions where there is a need for a quick response to treatment due to a mental or somatic state, for example acute catatonia, acute mania or psychotic depression, depressive stupor, especially when depression is life-threatening due to refusal to eat and cachexia, depression with thoughts and suicidal tendencies and neuroleptic malignant syndrome,

- conditions where the risk of using pharmacotherapy is greater than the risk associated with ECT, e.g. severe depression or psychosis in pregnancy, depression in a patient with agranulocytosis or leukopenia,

- situations in which, despite the use of pharmacotherapy, no improvement of the mental state in affective disorders or psychoses (drug resistance) was achieved,

- situations when the patient has responded well to ECT treatment in the past and / or when the patient prefers this form of treatment due to strong adverse effects associated with the conducted pharmacotherapy.[1]

In many Western countries, severe and treatment-resistant depression is the main indication for ECT. Schizophrenia is the number one indication for ECT worldwide, but is little used for this indication in Western countries. Older age, psychotic symptoms, and shorter episode duration as well as melancholic features and greater baseline depressive symptom severity are predictors of better ECT response.[5]

The decision to refer the patient to electroconvulsive treatment is made by a psychiatrist, after analyzing the current course of the disease, the current mental and somatic condition and obtaining the patient's consent. The commencement of treatments is preceded by a qualification procedure consisting in carrying out appropriate examinations and medical consultations. In each case, basic laboratory tests, ECG, EEG, fundus examination as well as internist, neurological and ophthalmological consultations are performed. The 
anaesthesiologist decides about the final qualification for treatment, after examining the patient and reading his medical documentation. This procedure allows to exclude possible contraindications to the use of this method of treatment.[6]

\section{CONTRAINDICATIONS}

There are few contraindications to the use of electroconvulsive therapy, however, in the presence of some serious comorbidities, electroconvulsive therapy should not be performed. Such diseases include: epilepsy and other severe brain diseases (e.g. encephalitis, diseases with increased intracranial pressure, condition after a recent stroke), severe heart diseases (up to six months after myocardial infarction), significant hypertension, severe disorders in the field of blood coagulation or significant anemia, advanced osteoporosis, aortic aneurysms, thrombophlebitis or some ophthalmic diseases.[6]

\section{SIDE EFFECTS}

A rare but serious complication of unmodified ECT was fracture or dislocation of the long bones.[2] Nowadays, aside from effects in the brain, the general physical risks of ECT are similar to those of brief general anesthesia.[7] The most commonly reported side effects by patients are mild, transient short-term memory impairment, headaches and muscle aches. These are temporary symptoms and do not always occur. These ailments usually disappear within 24 hours and do not require additional treatment. Few patients develop serious but manageable complications. The risk of developing life-threatening complications is approximately one in fifty thousand. This means that electroconvulsive treatment can be classified as a very safe therapeutic method. Deterioration of memory observed during and immediately after the end of therapy in some of the treated patients usually disappears after a month, less often after a few months. There are no grounds for concern that electroconvulsive treatments would cause permanent changes in personality.

During the electroconvulsive procedure itself, blood pressure spikes, cardiac arrhythmias, and breathing disorders may occur. Their frequency of occurrence is judged to be low; they usually appear in patients who have previously suffered from diseases or disorders of the cardiovascular and / or respiratory systems. These symptoms are often selflimiting or can be managed with standard therapeutic methods.[6]

\section{SUMMARY}

Although mechanism of action of electroconvulsive therapy is still not fully understood, ECT seems to be a very safe and effective treatment method of many psychiatric disorders. Widespread use of "modified", safer ECT has begun since introduction of suxamethonium (succinylcholine) in 1951, a safer synthetic alternative to curare. Films such as "One Flew Over the Cuckoo's Nest" or information about ECT as a method of "personality changing" turned out to be so popular that for several years the use of ECT was almost abandoned. Luckily, ECT became popular again, and nowadays doctors and patients can benefit from this method.

\section{REFERENCES}

1. Wpływ leczenia elektrowstrząsami na funkcje poznawcze w zaburzeniach depresyjnych. ResearchGate. Dostępne na: https://www.researchgate.net/publication/269395618_Wplyw_leczenia_elektrowstrzasami_na _funkcje_poznawcze_w_zaburzeniach_depresyjnych 
2. Antosik-Wójcińska AZ, Święcicki Ł. Terapia elektrowstrząsowa - skuteczna i bezpieczna alternatywa dla nieskutecznej farmakoterapii. Psychiatria. 2014;11(3):166-70.

3. Kiloh: Physical treatments in psychiatry - Google Scholar. Dostępne na: https://scholar.google.com/scholar_lookup?title=Physical+Treatments+in+Psychiatry\&public ation + year $=1988 \&$ author $=$ Kiloh $+\bar{L} .+$ G.\&author $=$ Smith + J. + S.\&author $=$ Johnson + G.F.\&pages $=277-333$

4. Barbara Fadem. Behavioral Science. Sixth edition. Wolters Kluwer Lippincott Williams \& Wilkins; 2014.

5. Kellner CH, Obbels J, Sienaert P. When to consider electroconvulsive therapy (ECT). Acta Psychiatrica Scandinavica. 2020;141(4):304-15.

6. Leczenie elektrowstrząsowe w Polsce. Polskie Towarzystwo Psychiatryczne. Dostępne na: https://psychiatria.org.pl/aktualnosci,tekst,397,leczenie_elektrowstrzasowe_w_polsce_update

7. Mental Health: A Report of the Surgeon General. Reports of the Surgeon General - Profiles in Science. Dostępne na: https://profiles.nlm.nih.gov/spotlight/nn/catalog/nlm:nlmuid101584932X120-doc 